\title{
Physicochemical characterization of passive films on niobium by admittance and electrochemical impedance spectroscopy studies
}

\author{
F. Di Quarto*, F. La Mantia, M. Santamaria \\ Dipartimento di Ingegneria Chimica, Università di Palermo, Viale delle Scienze, 90128 Palermo, Italy
}

Received 24 November 2004; received in revised form 10 March 2005; accepted 10 March 2005

Available online 28 June 2005

\begin{abstract}
An analysis of the electronic properties of amorphous semiconductor-electrolyte junction is reported for thin $\left(D_{\mathrm{ox}}<20 \mathrm{~nm}\right)$ passive film grown on $\mathrm{Nb}$ in acidic electrolyte. It will be shown that the theory of amorphous semiconductor-electrolyte junction (a-SC/El) both in the low band-bending and high band-bending regime is able to explain the admittance data of $\mathrm{a}-\mathrm{Nb}_{2} \mathrm{O}_{5} / \mathrm{El}$ interface in a large range $(10 \mathrm{~Hz}-10 \mathrm{kHz})$ of frequency and electrode potential values.

A modelling of experimental EIS data at different potentials and in the frequency range of $0.1 \mathrm{~Hz}-100 \mathrm{kHz}$ is presented based on the theory of amorphous semiconductor and compared with the results of the fitting of the admittance data obtained in a different experiment. Some preliminary insights on the possible dependence of the density of state (DOS) distribution on the mobile defects concentration and mechanism of growth of anodic film on valve metals are suggested.
\end{abstract}

(C) 2005 Elsevier Ltd. All rights reserved.

Keywords: Physicochemical characterization; Semiconductor-electrolyte junction; Electrochemical impedance spectroscopy

\section{Introduction}

It has been recently suggested that the electronic properties of passive films could be one of the key factors in controlling also the pitting behaviour of metals and alloys. Such a suggestion is in agreement with the importance of the electronic properties of electrode surface in determining the kinetics of charge transfer at the electrode-electrolyte interfaces [1].

Impedance spectroscopy (EIS) and differential capacitance study (Mott-Schottky analysis, M-S) are very popular techniques for the characterization of semiconductor/electrolyte interface $(\mathrm{SC} / \mathrm{El})$ as well as in studying the electronic properties of semiconducting passive films. These properties are frequently investigated by measuring the capacitance of the junction as a function of electrode potential and frequency of the superimposed ac signal. Although

\footnotetext{
* Corresponding author. Fax: +39 0916567280.

E-mail address: diquarto@dicpm.unipa.it (F. Di Quarto).
}

an investigation in a large range of frequencies is preferable for getting reliable information on the flat band potential, $V_{\mathrm{fb}}$, and donor or acceptor concentration of passive films, in many cases the study of electronic properties has been performed by using the $\mathrm{M}-\mathrm{S}$ analysis at only one frequency.

When such an approach is followed it happens that some meaningful physical information on the electronic properties are lost and more importantly in some cases erroneous estimate of characteristic levels of the junction (flat band potential, energy band location, etc.) are obtained. This makes more difficult to understand the kinetics of charge transfer at the interface. We stressed years ago that the frequency dependence of $\mathrm{M}-\mathrm{S}$ plots should be considered as a strong indication that the simple $\mathrm{M}-\mathrm{S}$ analysis based on the theory of perfect crystalline SC is, in many cases, misleading if used to get information on electronic properties of amorphous semiconducting passive films.

In the case of EIS data analysis, a first challenge arises in the choice of the equivalent circuit to be employed in fit- 
ting experimental data as well as on the physical meaning to attribute to the different passive elements of the electrical equivalent circuit. A further complication in the EIS analysis of amorphous passive films comes out by the fact that usually frequency independent space charge capacitance, $C_{\mathrm{SC}}$, are employed in the equivalent circuit by tacitly assuming that any frequency dependence derives from more exotic passive elements, whose physical meaning is sometimes obscure.

In previous papers [2-5], we proposed that a frequency dependence in $C_{\mathrm{SC}}$ or, more generally, in the admittance versus electrode potential curves could be a strong indication that a distribution of electronic states within the gap of material is present, and that such an occurrence is theoretically foreseen within the frame of a-SC theory. According to this we have shown that some of discrepancies usually encountered in the use of traditional M-S analysis of passive films/electrolyte interface could be overcome by a correct analysis of admittance data based on the theory of a-SC Schottky barrier [2-5]. In these papers a low band bending approach was used aimed to show the ability of the new approach in locating correctly the energy levels of the film/electrolyte junction and particularly in getting out an almost frequency-independent flat band potential value at different frequencies. In some of the previous works, it was shown that a density of states (DOS) distribution not constant in energy was present within the film and that such an important parameter could be also thickness dependent [1-5].

More recently in order to account for the differential capacitance behaviour of anodic a- $\mathrm{WO}_{3}$ films in a larger range of electrode potential, it was suggested that the theory of inverse metal-insulator-semiconductor (M-I-S) structure, valid for crystalline material, could be able to explain the observed behaviour [6]. Such an interpretation was challenged by the present authors who were able to show that the observed behaviour of a- $\mathrm{WO}_{3}$ passive film in a very large range of electrode potential values was compatible with the theory of amorphous semiconductor Schottky barrier including the high band-bending regime (HBB) [7]. The dissolution process observed during the permanence of a- $\mathrm{WO}_{3}$ passive film into the aqueous solution hampered to get a more quantitative information on the existence of spatial as well as energy dependence in the DOS distribution. At this aim we decided to come back to study the electronic properties of thin $(20 \mathrm{~nm})$ passive films on niobium owing to the fact that it could behave as a model system if we consider that:

(a) anodic film on $\mathrm{Nb}$ can be grown easily in a large range of electrode potential (i.e. thickness) and solution $\mathrm{pH}$ [8];

(b) anodic $\mathrm{Nb}_{2} \mathrm{O}_{5}$ films are amorphous in all range of thickness provided that anodization process is performed in absence of breakdown $[9,10]$;

(c) the stability of $\mathrm{a}-\mathrm{Nb}_{2} \mathrm{O}_{5}$ thin film is very good in acidic as well as in strong alkaline solutions [11].

Thus, a detailed analysis of EIS and admittance behaviour of amorphous semiconducting $\mathrm{Nb}_{2} \mathrm{O}_{5}$ film was performed based on the theory of a-SC Schottky barrier aimed to get information on DOS distribution both in energy and in space.

It will be shown that such a complex analysis, carried out both in a large domain of frequency and in a large range of potential, could provide more insight on DOS distribution and electronic properties of passive niobium helpful to a deeper comprehension of the mechanisms of growth and breakdown of passive films.

\section{Theoretical background on amorphous semiconductor Schottky barrier}

In order to understand the main differences in the behaviour of a-SC Schottky barrier with respect to the case of crystalline semiconductor (c-SC) it may be helpful to compare preliminarily the DOS distribution in both materials. In Fig. 1, we report the model of DOS distribution versus energy for generic amorphous and crystalline material. Although the general features of DOS distribution are preserved, specially if we compare Fig. 1a with c, some differences are evident and
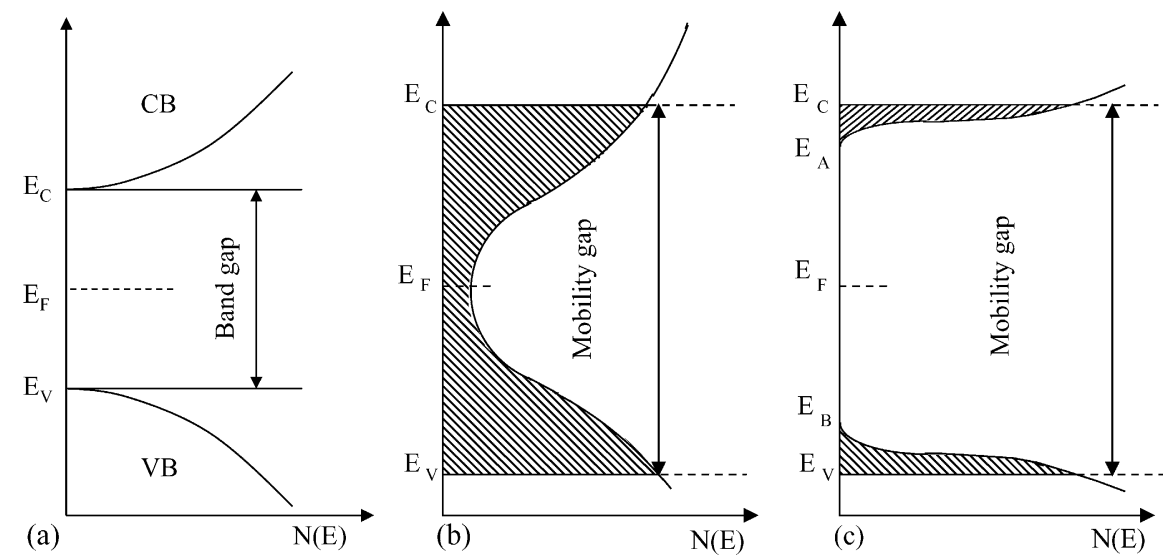

Fig. 1. Density of electronic states as a function of energy for amorphous and crystalline semiconductor: (a) crystalline semiconductor; (b) Cohen-Fritzsche-Ovishinsky model; (c) Mott and Davis model. Hatched areas represent the localized gap states, $E_{\mathrm{C}}$ and $E_{\mathrm{V}}$ are the conduction and valence band mobility edges, respectively. 

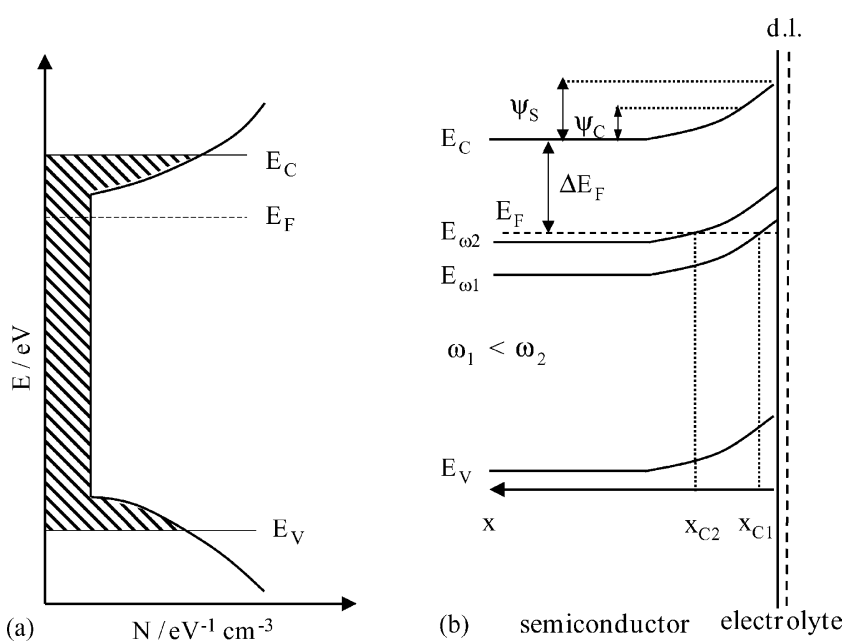

Fig. 2. (a) Schematic DOS distribution in a-SC and (b) energetics at an a-SC/El junction. The dashed area evidences localized electronic states.

they strongly affect the response of a-SC/El junction under ac electrical as well under light stimulus [12].

With respect to the impedance measurements the existence of deep tails of electronic states within the gap has a noticeable influence on the shape of space charge barrier as well as on the frequency response of such barrier [13]. This is better evidenced in Fig. 2 where the energetics of n-type a$\mathrm{SC} / \mathrm{El}$ interface is reported, under the simplifying hypothesis of constant DOS and spatially homogeneous material.

The main difference with respect to the case of crystalline $\mathrm{SC}$ is that the net space charge depends on both the ionized impurities and the localized states within the mobility gap. The electronic states lying into the gap (see Fig. 2) do not follow instantaneously the imposed ac signal, but they need a finite response time. This response time depends on their energy position with respect to the Fermi level and it can be much longer than the period of the ac signal having angular frequency $\omega$. In fact an exponential relaxation time, $\tau$, for the capture/emission of electrons from electronic states $E$ below $E_{\mathrm{F}}$ is assumed to hold according to the relationship:

$\tau=\tau_{0} \exp \left(\frac{E_{\mathrm{C}}-E}{k T}\right)$

where at constant temperature, $\tau_{0}$ is a constant characteristic of each material usually ranging between $10^{-14}$ and $10^{-10} \mathrm{~s}$. This means that, at constant band bending, with changing frequency the levels which can follow the signal change too. On the other hand, at constant ac frequency, by changing the band bending the more deep levels of depleted region lying below a critical level will not change the occupancy with ac signal. According to Eq. (1), by decreasing the energy of the localized state in the gap, $\tau$ increases sharply so that deep states (for which $\omega \tau \gg 1$ ) do not respond to the ac signal.

By assuming a full response for states satisfying the condition $\omega \tau \ll 1$ and a null response for states having $\omega \tau \gg 1$, a sharp cutoff energy level, $E_{\omega}$, separating states responding from those not responding to the signal, can be defined from the condition: $\omega \tau=1$, as:

$E_{\mathrm{C}}-E_{\omega}=-k T \ln \left(\omega \tau_{0}\right)$

According to Fig. 2 the intersection of $E_{\omega}$ with the Fermi level of material determines a characteristic point in the barrier, $x_{\mathrm{C}}$, at which corresponds a band bending $\psi_{\mathrm{C}}$ given by:

$|e| \psi_{\mathrm{C}}=|e| \psi\left(x_{\mathrm{C}}\right)=-k T \ln \left(\omega \tau_{0}\right)-\Delta E_{\mathrm{F}}$

where $\Delta E_{\mathrm{F}}=\left(E_{\mathrm{C}}-E_{\mathrm{F}}\right)_{\text {bulk }} \cdot x_{\mathrm{C}}$ is now a distance in the barrier which changes with changing frequency, $\omega$, and band bending $\psi_{\mathrm{S}}$. In particular, $x_{\mathrm{C}}$ increases with increasing frequency, at constant polarization, or with increasing polarization at constant frequency. From the theory it comes out that the total capacitance is sum of two series contribution coming from the $x<x_{\mathrm{C}}$ and $x>x_{\mathrm{C}}$ regions of the a-SC. The contribution to the conductance comes mainly from the region around $x=x_{\mathrm{C}}$ dividing the total response from null response regions. In the hypothesis of a constant DOS the total capacitance is given by the sum of the two contributions:

$\frac{1}{C\left(\psi_{\mathrm{S}}, \omega\right)}=\frac{1}{C\left(\psi_{\mathrm{C}}, 0\right)}+\frac{x_{\mathrm{C}}}{\varepsilon \varepsilon_{0}}$

where $C\left(\psi_{\mathrm{C}}, 0\right)=\sqrt{\varepsilon \varepsilon_{0} e^{2} N}$ and $x_{\mathrm{C}}=\sqrt{\frac{\varepsilon \varepsilon_{0}}{e^{2} N}} \ln \frac{\psi_{\mathrm{s}}}{\psi_{\mathrm{C}}}$. After substitution the following relationship is obtained for the total capacitance:

$C_{\mathrm{LBB}}\left(\psi_{\mathrm{S}}, \omega\right)=\sqrt{\varepsilon \varepsilon_{0} e^{2} N}\left(1+\ln \frac{\psi_{\mathrm{S}}}{\psi_{\mathrm{C}}}\right)^{-1}$

whilst the parallel conductance of the junction is given by:

$G_{\mathrm{LBB}}\left(\psi_{\mathrm{S}}, \omega\right)=\left(\frac{\omega \pi k T}{2}|e| \psi_{\mathrm{C}}\right) \sqrt{\varepsilon \varepsilon_{0} e^{2} N}\left(1+\ln \frac{\psi_{\mathrm{S}}}{\psi_{\mathrm{C}}}\right)^{-2}$

The analytical solutions for the admittance components of the junction have been derived under conditions that $\psi_{\mathrm{S}}>\psi_{\mathrm{C}} \geq 3 \mathrm{kT} / \mathrm{e}$ and at not too high band bending (low band-bending regime, $\left.e \psi_{\mathrm{S}}<\left(E_{\mathrm{g}} / 2-\Delta E_{\mathrm{F}}\right)\right)([1-5]$ and Refs. therein).

It has been shown that $G\left(\psi_{\mathrm{S}}, \omega\right)$ has a spectroscopic character with respect to the distribution of electronic states within the gap, whilst variations in DOS cause only minor changes in the $C\left(\psi_{\mathrm{S}}, \omega\right)$ versus potential plots provided that the DOS varies little over an energy range of $k T$. In previous equations $\varepsilon_{0}$ is the vacuum permittivity, $e$ the absolute value of the electronic charge, $\varepsilon$ the film dielectric constant and $\psi_{\mathrm{S}}$ is the potential drop inside the a-SC as above.

In high band-bending region, i.e. for $\psi_{\mathrm{S}}>V_{\mathrm{g}}=\left(E_{\mathrm{g}} / 2-\Delta E_{\mathrm{F}}\right) / e$, when a deep depletion region at the surface of a-SC/El junctions appears, according to Refs. [14-16] (see Fig. 3) the total capacitance of barrier can be modelled as a two series capacitance:

$\frac{1}{C\left(\psi_{\mathrm{S}}, \omega\right)}=\frac{1}{C\left(\psi_{\mathrm{g}}, \omega\right)}+\frac{x_{\mathrm{g}}}{\varepsilon \varepsilon_{0}}$ 


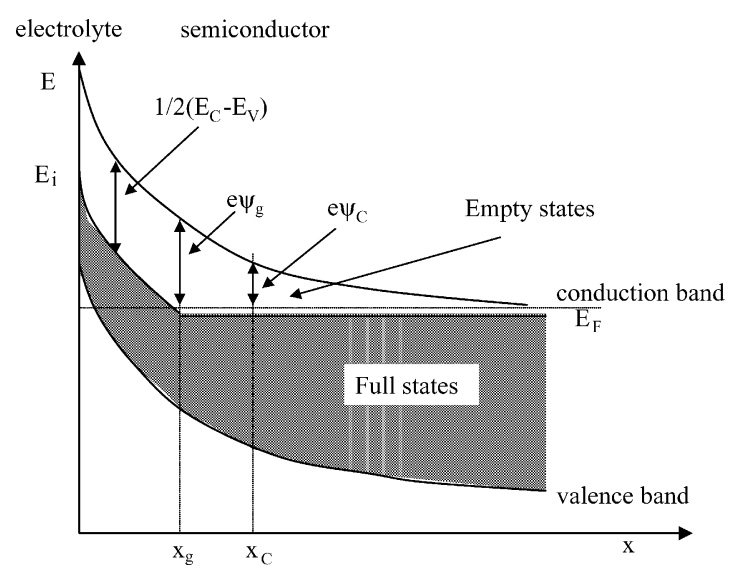

Fig. 3. Energy band diagram for an a-SC Schottky barrier under depletion conditions in the high band-bending region.

where the first term of Eq. (7) represents the low band bending contribution calculated at the electrode potential where the Fermi level crosses the mid gap energy and coincides with Eq. (4) after notation substitution. The second term represents the capacitance of the deep depletion region going from the surface to the point $x_{\mathrm{g}}$ of the junction (see Fig. 3), where a parabolic potential distribution exists, and is frequency independent.

In the hypothesis of constant DOS an analytical expression has been derived for $x_{\mathrm{g}}$ by Da Fonseca et al. [17], which allows to get the following analytical expression for the total capacitance:

$\frac{1}{C_{\mathrm{HBB}}\left(\omega, \psi_{\mathrm{S}}\right)}=\frac{1}{\sqrt{\varepsilon \varepsilon_{0} e^{2} N}}\left(\ln \frac{\psi_{\mathrm{g}}}{\psi_{\mathrm{C}}}+\sqrt{1+\frac{2}{\psi_{\mathrm{g}}}\left(\psi_{\mathrm{S}}-\psi_{\mathrm{g}}\right)}\right)$

It comes out from Eq. (8) that at high band bending the capacitance changes as the square root of the band bending as soon as the term $2 \psi_{\mathrm{S}} / \psi_{\mathrm{g}}$ becomes much higher than 1 . If this occurs a square root dependence from electrode potential can appear in the capacitance behaviour which could account for the M-S-like behaviour observed, sometimes, for a-SC/El junctions at high band bending.

Under the hypothesis of constant DOS, $N(E)=N$, it is also straightforward to derive from the general expression of $G\left(\psi_{\mathrm{S}}, \omega\right)$ (see Appendix A and Refs. [15,16]) the following equation for the conductance of the barrier [1]:

$$
\begin{aligned}
G_{\mathrm{HBB}}\left(\omega, \psi_{\mathrm{S}}\right)= & \pi^{2} f \frac{k T}{|e| \psi_{\mathrm{C}}} \sqrt{\varepsilon \varepsilon_{0} e^{2} N} \\
& \times\left(\ln \frac{\psi_{\mathrm{g}}}{\psi_{\mathrm{C}}}+\sqrt{1+\frac{2}{\psi_{\mathrm{g}}}\left(\psi_{\mathrm{S}}-\psi_{\mathrm{g}}\right)}\right)^{-2}
\end{aligned}
$$

Eqs. (8) and (9) have been derived under the same conditions valid for the LBB expression and they coincide with the previous ones for $\psi_{\mathrm{S}} \leq \psi_{\mathrm{g}}$.

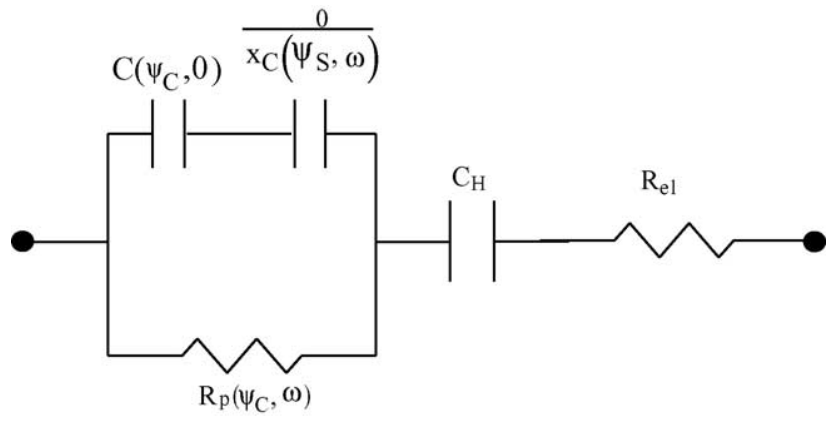

Fig. 4. Equivalent circuit by assuming an ideally polarizable interface and in absence of surface states contribution.

\section{Choice of the equivalent circuit of a-SC/El interface}

By assuming an ideally polarizable interface and in absence of surface states contribution to the measured impedance, it has been shown [2-5] for a series of amorphous semiconducting passive films ( $\left(\mathrm{a}-\mathrm{WO}_{3}, \mathrm{a}-\mathrm{Nb}_{2} \mathrm{O}_{5}, \mathrm{a}-\mathrm{TiO}_{2}\right)$ that the equivalent circuit reported in Fig. 4 was able to provide a fitting of the admittance behaviour in a large range of thickness and ac frequency. Moreover, such studies performed in the low band-bending region suggested that the DOS distribution was slightly changing in energy and decreasing with increasing film thickness [2-5].

More recently, in an attempt to fit the admittance curves of a- $\mathrm{WO}_{3}$ anodic films, we became aware [1,7] that the simple circuit of Fig. 4 was unable to explain the overall impedance behaviour of a-SC/El interface in a very large range of electrode potential (including the deep depletion region) and investigated frequencies $(0.1 \mathrm{~Hz}-100 \mathrm{kHz})$. It is worth to mention that in some cases with a- $\mathrm{WO}_{3}$, at not too high electrode potential and after long term stabilisation, a good fitting of EIS spectra in the $0.1 \mathrm{~Hz}-100 \mathrm{kHz}$ range was obtained by substituting a CPE element (with $n=0.98$ ) to the admittance of a-SC barrier.

In order to reduce the arbitrariness of the choice of the equivalent circuit and to account for possible charge transfer processes, we have chosen the equivalent circuit of Fig. 5, proposed by Gomes and Vanmaekelbergh [18,19], to account for the impedance behaviour of crystalline $\mathrm{SC} / \mathrm{El}$ interface in presence of electron charge transfer and/or recombination of electrons and holes trough surface states. Both processes could occur in the different potential regions where EIS spectra were obtained and by considering that the differential admittance measurements were performed in a very wide region of electrode potential, from the formation voltage, $U_{\mathrm{F}}$, close to the estimated $V_{\mathrm{fb}}$ potential, so encompassing the HBB and LBB regime.

A modification to the original circuit was made by:

(a) adding the conductance $G_{\mathrm{SC}}\left(\omega, \psi_{\mathrm{S}}\right)$ of a-SC barrier in parallel with $C_{\mathrm{SC}}\left(\omega, \psi_{\mathrm{S}}\right)$ according to the theory previously reported; 


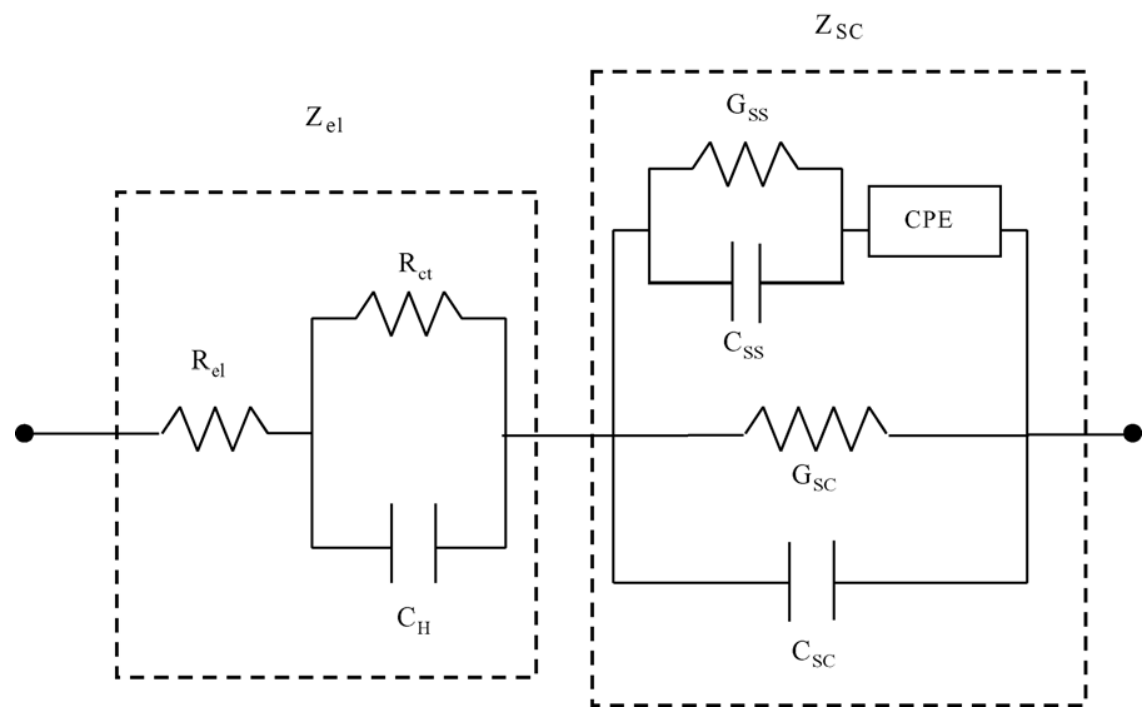

Fig. 5. Equivalent circuit for a-SC/El interface in presence of electron charge transfer and/or recombination of electrons and holes trough surface states.

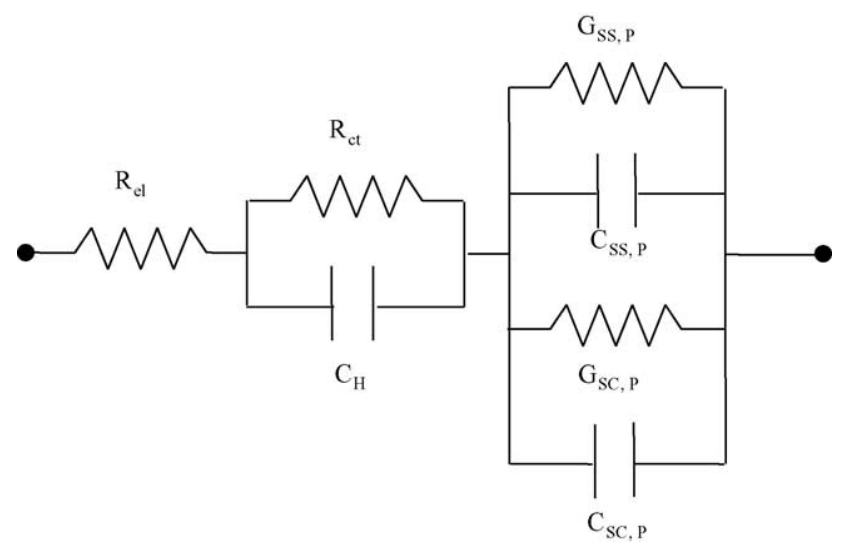

Fig. 6. Equivalent circuit employed in fitting differential admittance curves.

(b) substituting to the original $R_{1}$ resistance [19], in the arm of the circuit accounting for the charge transfer via localized states at the semiconductor surface, a CPE element which could account for the presence of a continuous distribution in energy of electronic states also at the surface of a-SC.

The equivalent circuit used for the analysis and fitting (see below) of the admittance plots is reported in Fig. 6, and it was derived from the previous one by means of series to parallel transformation of the arm in parallel to a-SC Schottky-barrier. The fitting procedure used to get the different elements of equivalent circuit will be described in a following section.

\section{Experimental}

Niobium (purity 99.9) rod from Goodfellow Metals (Cambridge) was used for the experiments. It was sealed into a teflon cylinder with an epoxy resin leaving a flat circular sur- face $(0.5 \mathrm{~cm}$ diameter $)$ in contact with the electrolyte. Before each experiment the metal surface was treated mechanically with abrasive paper followed by polishing with alumina powder $(0.5 \mu \mathrm{m})$, then electropolished in $\mathrm{HF} / \mathrm{H}_{2} \mathrm{SO}_{4}$ solution $(\Delta V=15 \mathrm{~V}$ for $45 \mathrm{~min}$ at $1500 \mathrm{rpm}$ ) and final cleaning in sonicated distilled water. The metal was then anodized at constant growth rate $\left(10 \mathrm{mV} \mathrm{s}^{-1}\right)$ in $0.5 \mathrm{M} \mathrm{H}_{2} \mathrm{SO}_{4}\left(U_{\mathrm{F}}=5 \mathrm{~V}(\mathrm{SCE})\right)$ using a potentiostat (EG\&G PAR 173) equipped with a signal generator (EG\&G PAR 175), and kept for $2 \mathrm{~h}$ to the formation voltage (stabilisation).

The capacitance of the junction during the growth of passive films was acquired by using a lock in amplifier (EG\&G 7260) technique by superimposing an ac signal of $10 \mathrm{mV} \mathrm{rms}$ at $1 \mathrm{kHz}$.

The impedance spectra and differential admittance curves were recorded by using a Parstat 2263 (PAR), connected to a computer for the data acquisition. The data were then processed according to the theory of a-SC and as reported in Appendix A.

For all the experiments a Pt net having a very high surface area was used as counter electrode.

\section{Results and discussion}

\subsection{Film formation}

In Fig. 7 we report the $C^{-1}$ versus formation voltage, $U_{\mathrm{F}}$, plot for anodic film on $\mathrm{Nb}$ grown at constant rate $\left(10 \mathrm{mV} \mathrm{s}^{-1}\right)$ in $0.5 \mathrm{M}$ sulphuric acid solution. From the slope of such a plot, it is possible to derive the anodizing ratio $A$, i.e. the inverse of anodizing electric field $A=1 / F_{\mathrm{el}}$, according to the relation:

$\frac{\mathrm{d}\left(\frac{1}{C}\right)}{\mathrm{d} U_{\mathrm{E}}}=\frac{A}{\varepsilon \varepsilon_{0}}$ 


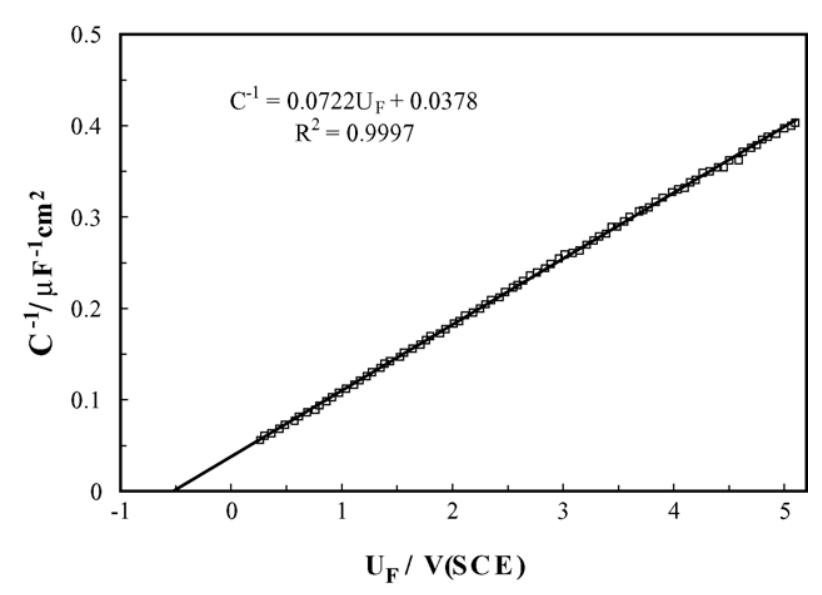

Fig. 7. $C^{-1}$ vs. formation voltage, $U_{\mathrm{F}}$, for an anodic film grown on $\mathrm{Nb}$ at constant rate $\left(10 \mathrm{mV} \mathrm{s}^{-1}\right)$ in $0.5 \mathrm{M}$ sulphuric acid solution.

where $\varepsilon$ is the dielectric constant of a- $\mathrm{Nb}_{2} \mathrm{O}_{5}$, assumed equal to $42[3,20]$ and $\varepsilon_{0}$ is the vacuum permittivity. An anodizing ratio of $26.8 \AA \mathrm{V}^{-1}$ was obtained in agreement with data reported in Refs. [3,9-11,21]. On the other hand a slightly lower anodizing ratio $\left(A=26.5 \AA^{-1}\right)$ was estimated by assuming an unitary efficiency of film formation and the relationship valid for growth under constant electric field:

$F_{\mathrm{el}}=\frac{1}{A}=\frac{z F \rho v}{\eta i M}$

where $v$ is voltage scan rate, $\rho=4.7 \mathrm{~g} \mathrm{~cm}^{-3}$ the film density [11], $M$ the molecular weight and the other symbols have their usual meaning. The difference in the value of anodizing ratio obtained with the two methods are within the $1 \%$ and it could be attributed to the presence of a very small electronic current which reduces the film formation efficiency, $\eta$, to $99 \%$.

It is worth to note that an anodizing ratio $\left(A=26.7 \AA \mathrm{V}^{-1}\right)$ almost coincident with the previous one was measured under otherwise identical conditions by using the $C^{-1}$ versus $U_{\mathrm{F}}$ slope and identical dielectric constant for film grown in $0.1 \mathrm{M}$ $\mathrm{NaOH}$ solution. A lower efficiency of film formation (96\%) was derived by using Eq. (10) in this last solution so that it seems reasonable to attribute such differences in film formation efficiency to differences in kinetics of oxygen evolution reaction in the two investigated electrolytes.

After reaching the chosen final voltage, $U_{\mathrm{F}}=5 \mathrm{~V}(\mathrm{SCE})$, the potential remained constant and a rapid decrease in the measured current was observed. During such stabilisation period $(\cong 2 \mathrm{~h}$ ) the film continued to grow at much lower rate and a very low current value $\left(0.3 \mu \mathrm{A} \mathrm{cm}^{-2}\right)$ was measured at the end of stabilisation. An estimate of the final thickness was obtained by measuring the total charge circulated during the stabilisation period and by using the Faraday law in the hypothesis of negligible electronic current $(\eta \geq 99 \%)$ and in absence of film dissolution [11]. The estimated thickness $\left(D_{\text {ox }}=193 \AA\right)$ at the end of this procedure is quite in agreement with data reported in literature for film grown at constant potential [9-11,21].

\subsection{Electrochemical impedance spectroscopy (EIS) data analysis}

After stabilisation the anodic film were investigated in $0.5 \mathrm{M} \mathrm{H}_{2} \mathrm{SO}_{4}$ electrolyte by means of EIS from the open circuit potential $U_{\mathrm{OC}}$ up to $5 \mathrm{~V}(\mathrm{SCE})$ in step of $1 \mathrm{~V}$ above $1 \mathrm{~V}$ and at $0.5 \mathrm{~V}(\mathrm{SCE})$. For a better reliability in the calculation of DOS distribution a further EIS measurement was performed at the fixed potential of $0.18 \mathrm{~V}$ (SCE). This was the lowest value of electrode potential at which the constraint $\psi_{\mathrm{S}}>\psi_{\mathrm{C}}$ (see Section 2) still holds at the lowest frequency $(0.1 \mathrm{~Hz})$ employed in EIS analysis (see Appendix A).

In separate experiments the curves of differential capacitance and conductance of a-SC/El junction as a function of $U_{\mathrm{E}}$ at different frequencies $(10 \mathrm{~Hz}-10 \mathrm{kHz})$ were obtained in a range of electrode potential starting from $5 \mathrm{~V}(\mathrm{SCE})$ down to $-0.25 \mathrm{~V}$ (SCE).

In Fig. 8 we report the impedance spectra, in the Bode representation, at different potential of a- $\mathrm{Nb}_{2} \mathrm{O}_{5} / \mathrm{H}_{2} \mathrm{SO}_{4}$ junction for a film grown in the same electrolyte according to the procedure described above. Regardless of the electrode potential the Bode diagram displays a similar behaviour with a characteristics inflection point in the module of the impedance
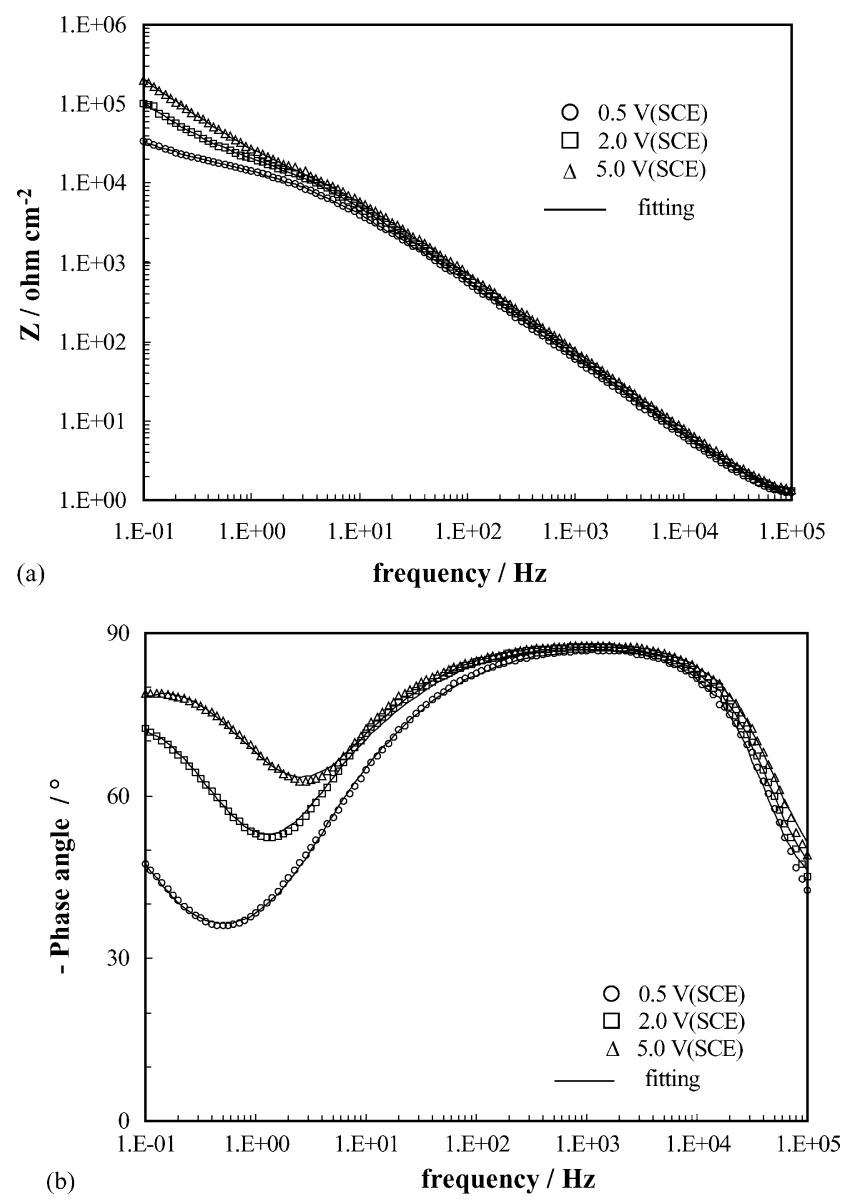

Fig. 8. Impedance spectra in the Bode representation at different potentials of a- $\mathrm{Nb}_{2} \mathrm{O}_{5} / \mathrm{H}_{2} \mathrm{SO}_{4}$ junction for a film grown in the same electrolyte to $5 \mathrm{~V}(\mathrm{SCE})$ at $10 \mathrm{mV} \mathrm{s}^{-1}$ after stabilisation. 


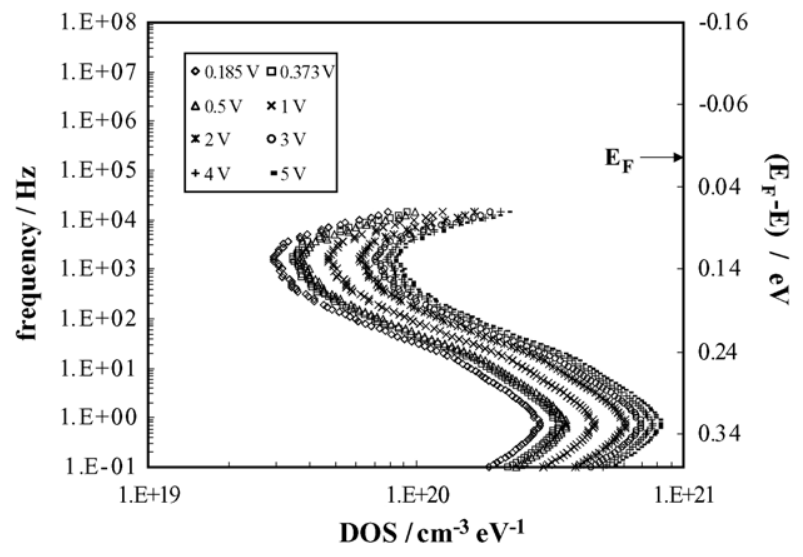

Fig. 9. DOS distribution vs. distance in energy (or frequency) from $E_{\mathrm{F}}$, obtained by fitting the impedance spectra at different $U_{\mathrm{E}}$ for the film of Fig. 8.

and a corresponding minimum in the phase versus frequency plots. We like to stress that the minimum in the $\phi^{\circ}$ versus $\log f$ plots shifts toward higher frequency and becomes less pronounced with increasing electrode potential. This finding seems to exclude as source of phase decreasing any film dissolution hypothesis, which could introduce in the equivalent circuit an inductance element. These features in Bode diagram remained unchanged also in presence of different redox couples (ferro/ferricyanide and $\mathrm{Ce}^{4+} / \mathrm{Ce}^{3+}$ ). In particular, although the phase value at the minimum was a little depending on the redox couple, its position as a function of frequency was almost independent from the nature of redox couple in solution.

In Fig. 9 we report the DOS distribution, as a function of distance in energy (or frequency) from $E_{\mathrm{F}}$, obtained by fitting the impedance spectra of the sample at various $U_{\mathrm{E}}$. More details on this procedure can be found in Appendix A. The different DOS distribution, obtained at each potential, shows that a minimum in DOS is present at around $1.5 \mathrm{kHz}$ corresponding to a distance in energy from $E_{\mathrm{F}}$ of about $0.12 \mathrm{eV}$. The maximum in DOS appears located close to the lowest limit of frequency range investigated and precisely at around $0.4 \mathrm{~Hz}$, which corresponds to a distance in energy from $E_{\mathrm{F}}$ of about $0.33 \mathrm{eV}$. From such a figure it comes out also that DOS distribution changes with the potential in an appreciable way in the range of frequency comprised between 10 and $10 \mathrm{kHz}$ and in agreement with a variation of DOS along the film. In fact, although the shape of the DOS does not change with changing potential (see Fig. 9), it is possible to see that the fitting of impedance spectra at more anodic potentials was possible by assuming increasing values in DOS distribution as clearly evidenced in the same figure. This last aspect will be better evidenced in the following section where the fitting of differential admittance curves $\left(C_{\mathrm{SC}}\left(\omega, \psi_{\mathrm{S}}\right)\right.$ and $G_{\mathrm{SC}}(\omega$, $\psi_{\mathrm{S}}$ ) versus $U_{\mathrm{E}}$ ) will be presented and discussed.

In Table 1 we report the parameters used for fitting the impedance spectra at different potentials corresponding to the DOS distribution displayed in previous Fig. 9. We like to mention that a very good fitting of impedance spectra was possible by keeping constant the double layer capacitance $\left(C_{\mathrm{dl}}=18.8 \mu \mathrm{F} \mathrm{cm}^{-2}\right)$ and equal to values expected for this parameter. An almost constant differential charge transfer resistance was obtained in a large range of electrode potentials $(2-5 \mathrm{~V}(\mathrm{SCE}))$ where $\mathrm{a}_{-} \mathrm{Nb}_{2} \mathrm{O}_{5} /$ El junction is biased in deep depletion region. As for the other elements of the equivalent circuit representing the arm in parallel with the admittance of a-SC, we like to stress that $\mathrm{CPE}\left(Y_{\mathrm{cpe}}=Q(i \omega)^{n}\right)$ element is almost coincident with a resistor $(n=0.15)$ in all range of investigated electrode potentials, whilst the $C_{\mathrm{SS}}$ element changes noticeably with changing band-bending by increasing two order of magnitude on going from deep depletion condition down to $U_{\mathrm{OC}}$.

In order to have a better view of the influence of this arm of equivalent circuit on the differential admittance curves of the junction, it is convenient to convert this arm to the parallel scheme reported in Fig. 6. According to this scheme the admittance of the junction, after correction for the $\left(Z_{\mathrm{el}}\right)$ elements of Fig. 5, consists of a total conductance sum up of $G_{\mathrm{SC}, \mathrm{P}}\left(\omega, \psi_{\mathrm{S}}\right)$ and $G_{\mathrm{SS}, \mathrm{P}}\left(\omega, \psi_{\mathrm{S}}\right)$, and a total parallel capacitance given by the sum of $C_{\mathrm{SC}, \mathrm{P}}\left(\omega, \psi_{\mathrm{S}}\right)$ plus the $C_{\mathrm{SS}, \mathrm{P}}\left(\omega, \psi_{\mathrm{S}}\right)$, derived from the series to parallel transformation of the arm and accounting for the role of surface states in the equivalent circuit.

By looking to the data of Table 2 containing the $C_{\mathrm{SS}, \mathrm{P}}$ and $G_{\mathrm{SS}, \mathrm{P}}$ values as a function of frequency in the range $10 \mathrm{~Hz}-10 \mathrm{kHz}$, the same employed in the differential admittance studies, but at constant potential, $U_{\mathrm{E}}=5$ and $0.185 \mathrm{~V}(\mathrm{SCE})$, it is possible to reach the following preliminary conclusions useful for the analysis of differential admittance data:

Table 1

Parameters employed for the fitting of the impedance spectra at different potentials corresponding to the DOS distribution displayed in Fig. 9

\begin{tabular}{|c|c|c|c|c|c|c|c|}
\hline$\overline{U_{\mathrm{E}}(\mathrm{V}(\mathrm{SCE}))}$ & $R_{\mathrm{S}}\left(\Omega \mathrm{cm}^{2}\right)$ & $C_{\mathrm{dl}}\left(\times 10^{-5} \mathrm{~F} \mathrm{~cm}^{-2}\right)$ & $R_{\mathrm{ct}}\left(\times 10^{3} \Omega \mathrm{cm}^{2}\right)$ & $C_{\mathrm{SS}}\left(\mathrm{F} \mathrm{cm}^{-2}\right)$ & $Q_{\mathrm{SS}}\left(\times 10^{-5} \mathrm{~S} \mathrm{~cm}^{-2}\right)$ & $n_{\mathrm{SS}}$ & $G_{\mathrm{SS}}\left(\mathrm{S} \mathrm{cm}^{-2}\right)$ \\
\hline 0.185 & 0.55 & 1.88 & 1.03 & $4.75 \times 10^{-4}$ & 6.25 & 0.15 & $3.20 \times 10^{-5}$ \\
\hline 0.38 & 0.55 & 1.88 & 1.86 & $1.05 \times 10^{-4}$ & 5.40 & 0.15 & $1.80 \times 10^{-5}$ \\
\hline 0.5 & 0.55 & 1.88 & 2.10 & $7.50 \times 10^{-5}$ & 4.50 & 0.15 & $8.00 \times 10^{-6}$ \\
\hline 1 & 0.55 & 1.88 & 2.55 & $2.95 \times 10^{-5}$ & 3.85 & 0.15 & $3.00 \times 10^{-6}$ \\
\hline 2 & 0.55 & 1.88 & 2.16 & $1.25 \times 10^{-5}$ & 3.20 & 0.15 & $1.30 \times 10^{-6}$ \\
\hline 3 & 0.55 & 1.88 & 2.17 & $7.50 \times 10^{-6}$ & 3.20 & 0.15 & $8.00 \times 10^{-7}$ \\
\hline 4 & 0.55 & 1.88 & 2.12 & $5.50 \times 10^{-6}$ & 3.20 & 0.15 & $5.70 \times 10^{-7}$ \\
\hline 5 & 0.55 & 1.88 & 2.18 & $4.70 \times 10^{-6}$ & 3.20 & 0.15 & $5.70 \times 10^{-7}$ \\
\hline
\end{tabular}


Table 2

$G_{\mathrm{SS}, \mathrm{P}}$ and $C_{\mathrm{SS}, \mathrm{P}}$ values(see Fig. 6) derived from EIS as a function of frequency and potential

\begin{tabular}{|c|c|c|c|c|}
\hline \multirow[t]{2}{*}{$f(\mathrm{~Hz})$} & \multicolumn{2}{|l|}{$U_{\mathrm{E}}=0.185 \mathrm{~V}(\mathrm{SCE})$} & \multicolumn{2}{|l|}{$U_{\mathrm{E}}=5 \mathrm{~V}(\mathrm{SCE})$} \\
\hline & $G_{\mathrm{SS}, \mathrm{P}}\left(\times 10^{-4} \mathrm{~S} \mathrm{~cm}^{-2}\right)$ & $C_{\mathrm{SS}, \mathrm{P}}\left(\mu \mathrm{F} \mathrm{cm}^{-2}\right)$ & $G_{\mathrm{SS}, \mathrm{P}}\left(\times 10^{-5} \mathrm{~S} \mathrm{~cm}^{-2}\right)$ & $C_{\mathrm{SS}, \mathrm{P}}\left(\mu \mathrm{F} \mathrm{cm}^{-2}\right)$ \\
\hline 10 & 1.13 & 0.439 & 5.10 & 0.363 \\
\hline 100 & 1.60 & 0.061 & 8.07 & 0.035 \\
\hline 1000 & 2.26 & 0.009 & 11.5 & 0.045 \\
\hline 10000 & 3.19 & 0.001 & 16.3 & 0.006 \\
\hline
\end{tabular}

(a) The total parallel capacitance of equivalent circuit depicted in Fig. 6 can be assumed as coincident with $C_{\mathrm{SC}, \mathrm{P}}\left(\omega, \psi_{\mathrm{S}}\right)$ in the all range of investigated potentials and within the limits of validity of the theory of a-SC $\left(\psi_{\mathrm{S}}>\psi_{\mathrm{C}}\right)$ for $f \geq 100 \mathrm{~Hz}$. At this frequency the neglect of $C_{\mathrm{SS}, \mathrm{P}}$ introduces an error in the $C_{\mathrm{SC}, \mathrm{P}}\left(\omega, \psi_{\mathrm{S}}\right)$ value less than $2 \%$. Such an error becomes less than $1 \%$ at $200 \mathrm{~Hz}$ and is completely negligible at still higher frequencies.

(b) The contribution of $G_{\mathrm{SS}, \mathrm{P}}$ to the total conductance is relevant at lower frequencies but not negligible neither at the highest frequency used in our measurements $(10 \mathrm{kHz})$ and specially at the high electrode potentials where this contribution reaches its maximum. However, a detailed inspection of $G_{\mathrm{SS}, \mathrm{P}}$ data, in the all frequency and electrode potential range, suggests that a simple and reasonably good correction procedure of the differential admittance curves for deriving the $G_{\mathrm{SC}, \mathrm{P}}$ curves is to subtract to the total parallel conductance the $G_{\mathrm{SS}, \mathrm{P}}$ value obtained at $U_{\mathrm{E}}=5 \mathrm{~V}(\mathrm{SCE})$. We have to mention that, owing to a constancy of $G_{\mathrm{SS}, \mathrm{P}}$ in a rather large range of potential $\left(2 \leq U_{\mathrm{E}} \leq 5 \mathrm{~V}(\mathrm{SCE})\right)$, the procedure above mentioned allowed to get reliable value of DOS for each frequency as a function of band bending in a large region of film thickness. More details on these aspects will be discussed in the following section.

\subsection{Differential admittance (DA) study}

In order to highlight the need of a different approach in the analysis of the differential capacitance data we report in Fig. 10 the $\mathrm{M}-\mathrm{S}$ plots of a- $\mathrm{Nb}_{2} \mathrm{O}_{5}$ film previously investigated by EIS analysis. As previously reported for other semiconductor passive films a very short range of linearity (around $0.2 \mathrm{~V}$ ) is displayed by the curves in the low band-bending region, which could be used to get a rough estimate of the flat band potential (around $-0.24 \mathrm{~V}(\mathrm{SCE})$ ). A close inspection of such plots near the flat band potential showed a rather large scattering $(0.1 \mathrm{~V})$ of $V_{\mathrm{fb}}$ values if the true straight line region was used in the extrapolation. However, more importantly than the disturbingly limited straight-line region, we like to stress that such a behaviour is not compatible with simple $\mathrm{M}-\mathrm{S}$ analysis of crystalline SC/electrolyte junction usually employed to derive both the $V_{\mathrm{fb}}$ and the donor concentration in passive films. Moreover, the large frequency dependency and the shape of $\mathrm{M}-\mathrm{S}$ plots are not easily amenable to any of possible behaviour of crystalline SC containing discrete deep level of donors. We have to mention that still more puzzling behaviour, in the frame of classical M-S analysis, could be observed in the capacitance behaviour of thicker films as previously reported in Refs. [2,3].

According to this an analysis of the differential admittance data was performed on the basis of the a-SC Schottky barrier theory and by taking into account the results of the EIS study.

As previously discussed, the simplified equivalent circuit of Fig. 6 could be employed in the analysis of differential admittance data if we limit initially the analysis between 100 and $10 \mathrm{kHz}$, where the $C_{\mathrm{SS}, \mathrm{P}}$ term is negligible (less than $2 \%$ in the all potential and frequency ranges). According to this the differential admittance data were initially transformed in a series equivalent circuit in order to subtract $Z_{\mathrm{el}}$ to $\left(Z_{\mathrm{el}}+Z_{\mathrm{SC}}\right)$. Thereafter, the residual impedance was transformed back to the parallel configuration and analysed by neglecting $C_{\mathrm{SS}, \mathrm{P}}\left(\omega, U_{\mathrm{E}}\right)$ contribution to the admittance of the a-SC Schottky barrier. Moreover, as anticipated in the last section, although a good fitting of the conductance plots could be obtained by a simple subtraction of the $G_{\mathrm{SS}, \mathrm{P}}(\omega$, $U_{\mathrm{F}}$ ) value measured at $U_{\mathrm{F}}$, for these frequencies we corrected the overall curve by subtracting the values of $G_{\mathrm{SS}, \mathrm{P}}$ obtained from EIS analysis and by interpolating them in the region where a not constant behaviour was observed. This last procedure was preferred because a good interpolating function was found for these frequencies and the resulting conductance curve was still well behaving owing to the fact that the correction terms were at any potential only a small fraction of the experimental values. This was not possible for

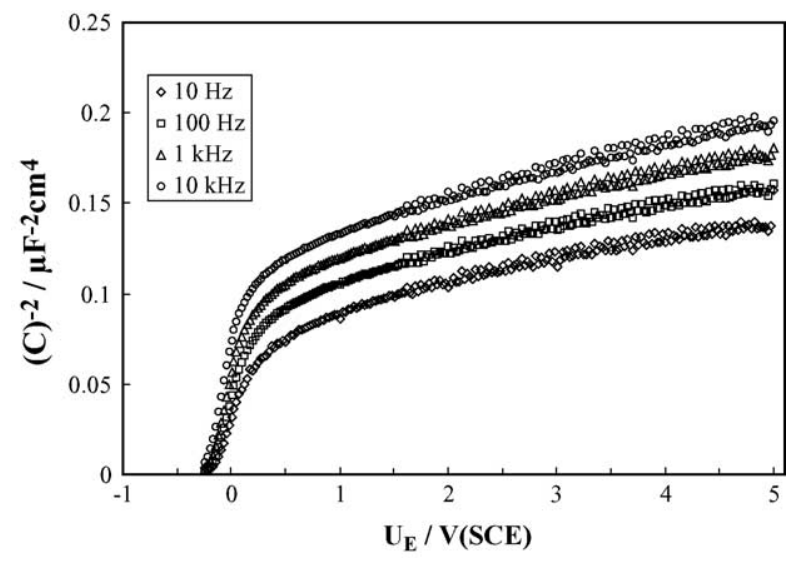

Fig. 10. $C^{-2}$ vs. $U_{\mathrm{E}}$ plots at different frequencies for the film of Fig. 8. 

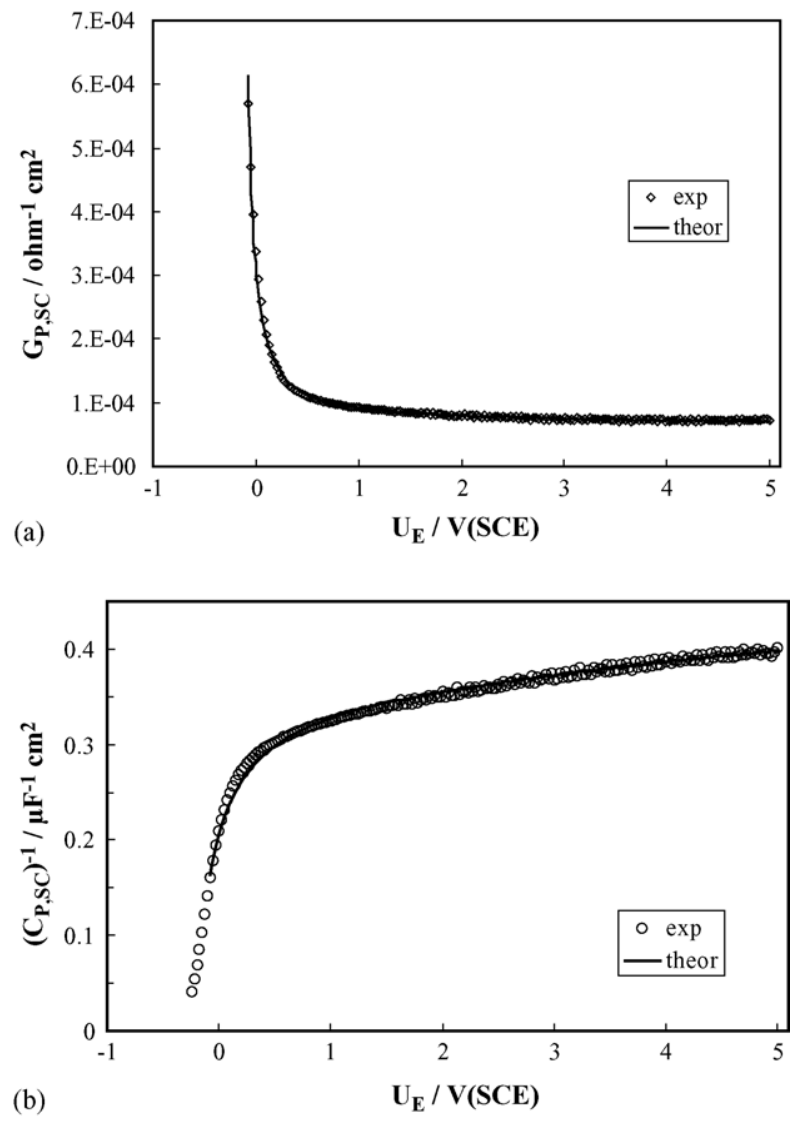

Fig. 11. Fitting of the experimental admittance curves of a- $\mathrm{Nb}_{2} \mathrm{O}_{5}$ $\left(f=100 \mathrm{~Hz}\right.$; scan rate $=10 \mathrm{mV} \mathrm{s}^{-1}$, sol: $\left.0.5 \mathrm{M} \mathrm{H}_{2} \mathrm{SO}_{4}\right)$. (a) $G_{\mathrm{P}, \mathrm{SC}}$ vs. $U_{\mathrm{E}}: e \psi_{\mathrm{C}}=0.20 \mathrm{eV}$ and $V_{\mathrm{fb}}=-0.245 \mathrm{~V}(\mathrm{SCE}) ;\left(\right.$ b) $\left(C_{\mathrm{P}, \mathrm{SC}}\right)^{-1}$ vs. $U_{\mathrm{E}}$ : $e \psi_{\mathrm{C}}=0.20 \mathrm{eV}$ and $V_{\mathrm{fb}}=-0.245 \mathrm{~V}(\mathrm{SCE})$.

the curve at $10 \mathrm{~Hz}$, because at this frequency the $G_{\mathrm{SS}, \mathrm{P}}$ values to be subtracted (determined by EIS in separate experiments) were a larger fraction of the measured $G_{\mathrm{SC}}\left(\omega, \psi_{\mathrm{S}}\right)$ and small error in $G_{\mathrm{SS}, \mathrm{P}}$ affected in a rather unpredictable way the low band-bending region of measured conductance values in the differential admittance experiments. This is not surprising because in the low band-bending region large contribution from $C_{\mathrm{SS}}$ and $\mathrm{CPE}$ elements to $G_{\mathrm{SS}, \mathrm{P}}$ are expected theoretically and at low frequencies such contributions become quantitatively larger than the value of $G_{\mathrm{SC}}$ to be measured. For these reasons in a first quantitative analysis of differential admittance data in a large range of electrode potential we preferred to analyse the higher frequency region $(f \geq 100 \mathrm{~Hz})$. The values of $G_{\mathrm{SS}, \mathrm{P}}\left(\omega, U_{\mathrm{E}}\right)$ to be subtracted are those derived from EIS data reported in Table 1 after series to parallel transformation.

In Figs. 11 and 12 we report the differential admittance curves of the $\mathrm{a}-\mathrm{Nb}_{2} \mathrm{O}_{5} / \mathrm{El}$ junction, at different frequencies as a function of the electrode potential obtained, for the film previously studied by EIS. In the same figures we report the fitting curves as well as the parameters used in the fitting procedure according to the equations of amorphous Schottky barrier previously reported (see also Appendix A).
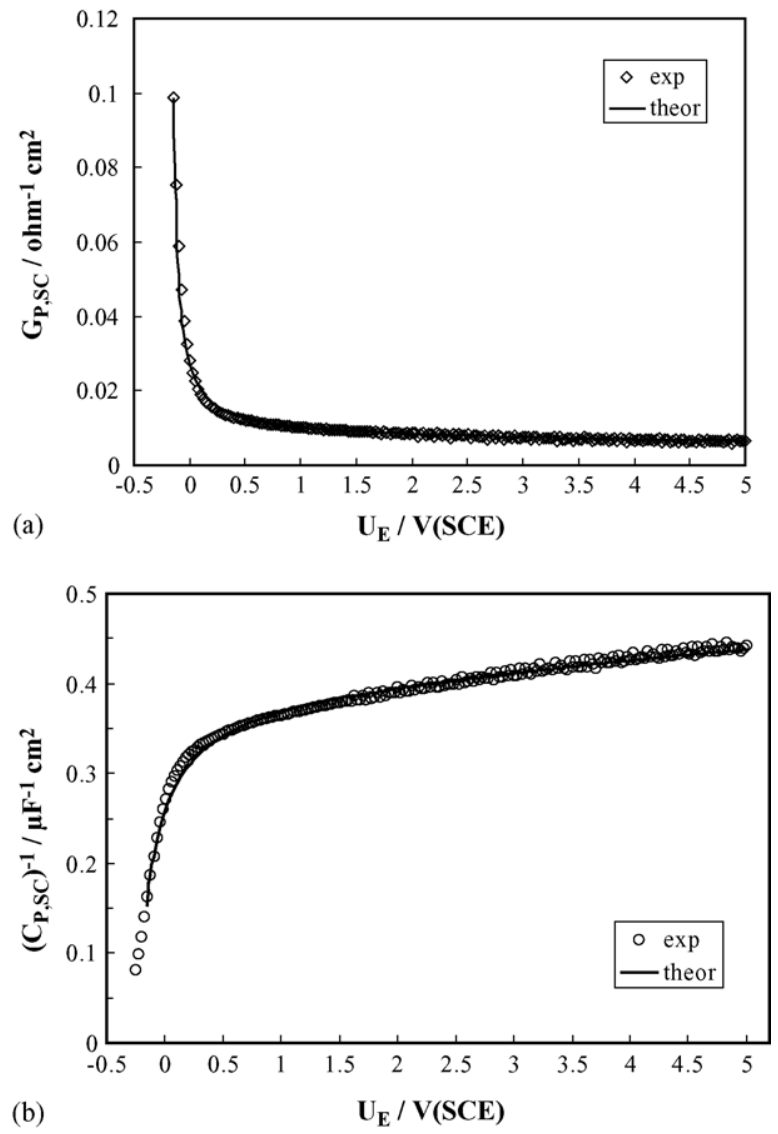

Fig. 12. Fitting of the experimental admittance curves of $\mathrm{a}-\mathrm{Nb}_{2} \mathrm{O}_{5}$ $\left(f=10 \mathrm{kHz}\right.$; scan rate $=10 \mathrm{mV} \mathrm{s}^{-1}$, sol: $\left.0.5 \mathrm{M} \mathrm{H}_{2} \mathrm{SO}_{4}\right)$. (a) $G_{\mathrm{P}, \mathrm{SC}}$ vs. $U_{\mathrm{E}}: e \psi_{\mathrm{C}}=0.08 \mathrm{eV}$ and $V_{\mathrm{fb}}=-0.228 \mathrm{~V}(\mathrm{SCE}) ;\left(\right.$ b) $\left(C_{\mathrm{P}, \mathrm{SC}}\right)^{-1}$ vs. $U_{\mathrm{E}}$ : $e \psi_{\mathrm{C}}=0.08 \mathrm{eV}$ and $V_{\mathrm{fb}}=-0.225 \mathrm{~V}(\mathrm{SCE})$.

The fitting of admittance data of a- $\mathrm{Nb}_{2} \mathrm{O}_{5}$ thin films, by using a constant DOS in Eqs. (8) and (9), could be performed in a rather limited potential range (about $0.5 \mathrm{~V}$ ). This was at variance with the case of a- $\mathrm{WO}_{3}$ [7], when the use of an almost constant DOS in Eqs. (8) and (9) was able to fit reasonably well the differential capacitance plot in a $10 \mathrm{~V}$ range of electrode potential values in high frequency range. We have to mention that differential capacitance curves for thicker films of a- $\mathrm{Nb}_{2} \mathrm{O}_{5}$ were fitted in the low band bending (up to about $2 \mathrm{~V})$ regime by using a constant DOS [2,3]. A possible rationale for such a behaviour will be presented in the following after discussing the behaviour of DOS as a function of film thickness.

In Fig. 13, we report the DOS distribution, derived from fitting the capacitance data for the three employed frequencies $(100 \mathrm{~Hz}-10 \mathrm{kHz})$, as a function of the equivalent space charge region of a-SC calculated according to the equation:

$x_{\mathrm{SC}}=\frac{\varepsilon \varepsilon_{0}}{C_{\mathrm{SC}}\left(\psi_{\mathrm{S}}, \omega\right)}$

As previously mentioned, the DOS distribution derived from the capacitance measurements is a spatially averaged value, whilst a more spectroscopic character is associated to the 


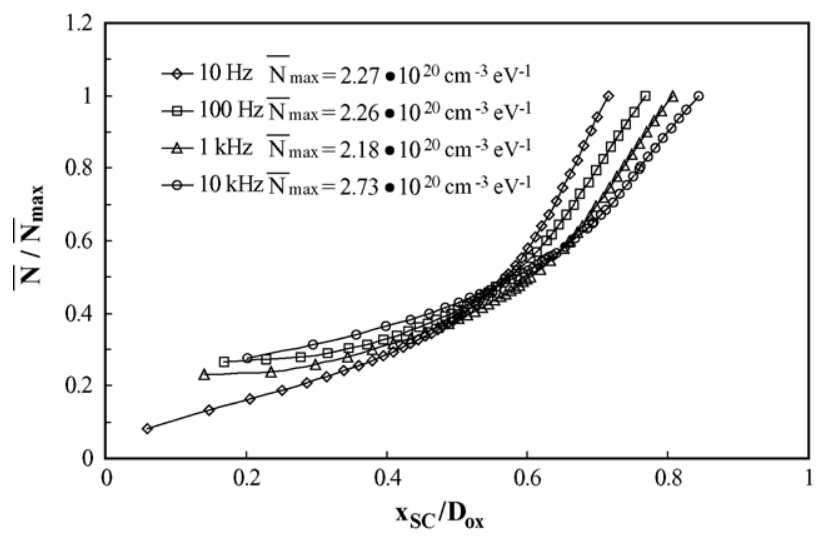

Fig. 13. Spatial dependence of DOS derived from the fitting of the differential capacitance curves.

DOS distribution derived from the differential conductance [14-16]. According to this we derived the DOS distribution (see Fig. 14) at $x_{\mathrm{C}}$ by using the conductance plots and Eq. (A.5) in Appendix A. $x_{\mathrm{C}}$ was calculated as:

$x_{\mathrm{C}}=x_{\mathrm{SC}}-\frac{\varepsilon \varepsilon_{0}}{C_{\mathrm{SC}}\left(\psi_{\mathrm{C}}, 0\right)}$

From the data fitting it comes out that for these frequencies an almost constant flat band potential $\left(V_{\mathrm{fb}}=-0.24 \pm 0.015 \mathrm{~V}(\mathrm{SCE})\right)$ was measured from both conductance and capacitance plots. We anticipate that such a flat band potential was also valid for fitting the differential admittance data derived at $10 \mathrm{~Hz}$. This means that for a large range of frequency encompassing three decades we have been able to get an almost constant flat band potential from admittance curves of a- $\mathrm{Nb}_{2} \mathrm{O}_{5}$. We like to mention that such a value of $V_{\mathrm{fb}}$ was also in very good agreement with that obtained from the fitting of photocurrent versus potential curves measured for the same junction (Fig. 15a and b).

The fitting of admittance curves at $10 \mathrm{~Hz}$ was finally performed by using the more general equivalent parallel circuit containing also the $C_{\mathrm{SS}, \mathrm{P}}$ element (Fig. 6). In this case the simplification of neglecting the change in $C_{\mathrm{SS}, \mathrm{P}}$ and $G_{\mathrm{SS}, \mathrm{P}}$

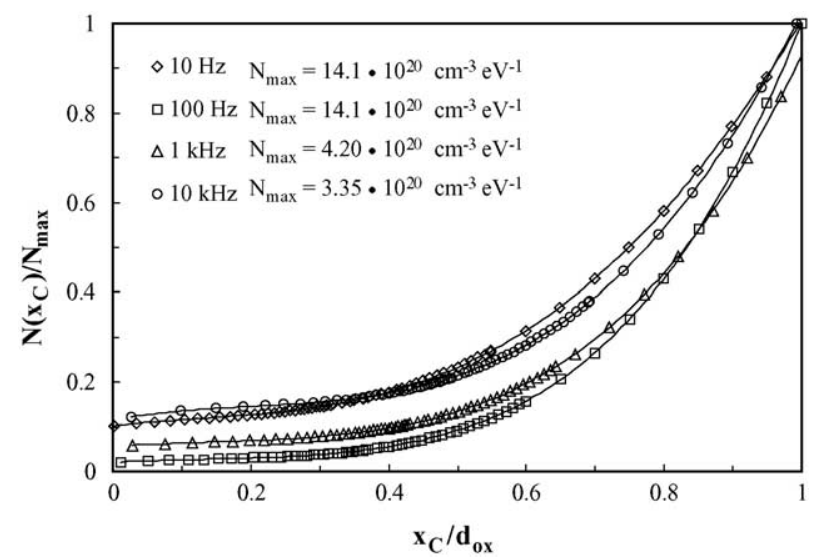

Fig. 14. DOS at $x_{\mathrm{C}}$ derived from the fitting of the differential conductance curves.
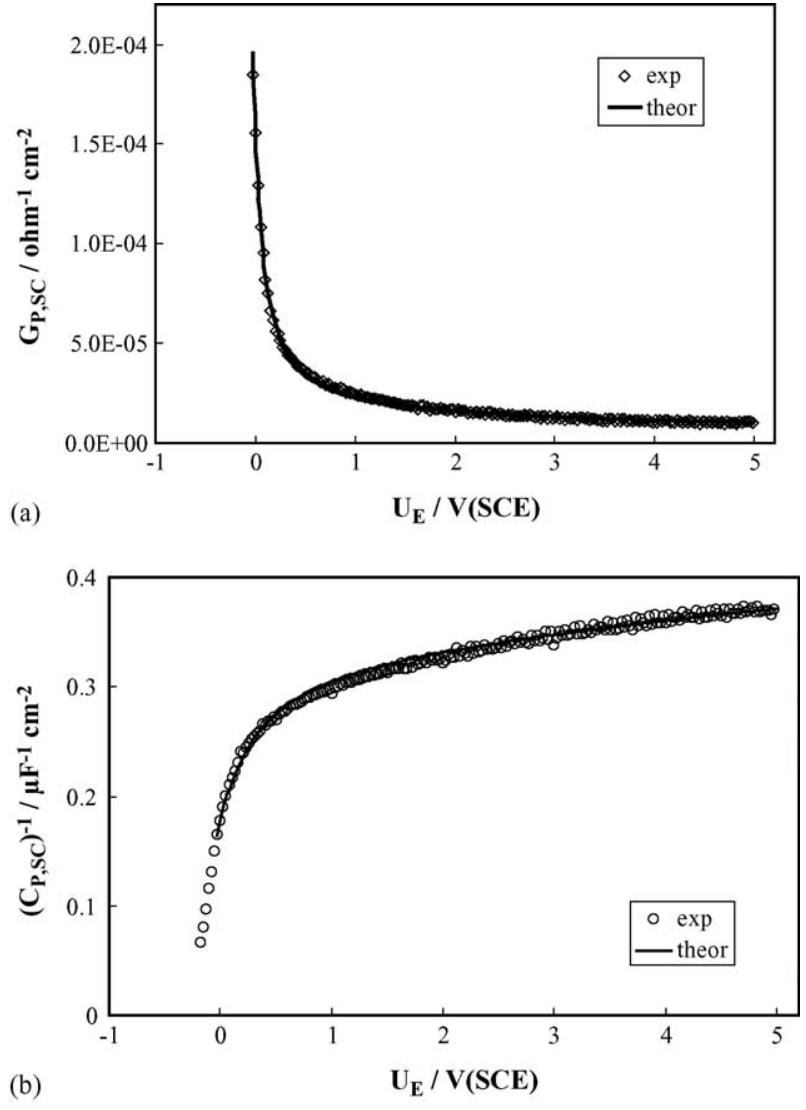

Fig. 15. Fitting of the experimental admittance curves of a- $\mathrm{Nb}_{2} \mathrm{O}_{5}(f=10 \mathrm{~Hz}$; scan rate $=10 \mathrm{mV} \mathrm{s}^{-1}$, sol: $0.5 \mathrm{M} \mathrm{H}_{2} \mathrm{SO}_{4}$ ). (a) $G_{\mathrm{P}, \mathrm{SC}}$ vs. $U_{\mathrm{E}}: e \psi_{\mathrm{C}}=0.26 \mathrm{eV}$ and $V_{\mathrm{fb}}=-0.240 \mathrm{~V}(\mathrm{SCE})$; (b) $\left(C_{\mathrm{P}, \mathrm{SC}}\right)^{-1}$ vs. $U_{\mathrm{E}}: e \psi_{\mathrm{C}}=0.26 \mathrm{eV}$ and $V_{\mathrm{fb}}=-0.230 \mathrm{~V}(\mathrm{SCE})$.

as a function of potential was introduced. According to this, constant values of $C_{\mathrm{SS}, \mathrm{P}}$ and $G_{\mathrm{SS}, \mathrm{P}}$, derived from EIS data at $U_{\mathrm{E}}=5 \mathrm{~V}(\mathrm{SCE})$, were subtracted to the parallel conductance and capacitance. Such a procedure affects negligibly the $C_{\mathrm{SC}, \mathrm{P}}$ values in the all range of potential but still leave some appreciable errors in the $G_{\mathrm{SC}, \mathrm{P}}$ values at low potentials (see above). This fact could affect in some way the $V_{\mathrm{fb}}$ values derived from fitting $G_{\mathrm{SC}, \mathrm{P}}$ curves as well as the value of DOS, deeper in energy, derived at low $x_{\mathrm{C}}$ values (i.e. close to the film surface). As for $V_{\mathrm{fb}}$, however, the changes should be in the order of $k T / e$, thus remaining within the usual uncertainty with which such a parameter is measured. As for the DOS distribution, although its dependence from $x_{\mathrm{C}}$ does not change appreciably, the values estimated at various $x_{\mathrm{C}}$ could change sensibly depending on the entity of correction performed on $G_{\mathrm{SC}}$ at lower potential.

However, our estimate poses such correction in the DOS value around $50 \%$ at $x_{\mathrm{C}}=0$. Nevertheless, we have to mention that the value of DOS derived from $G_{\mathrm{SC}, \mathrm{P}}$ by assuming $G_{\mathrm{SS}, \mathrm{P}}$ constant and reported in Fig. 16 agreed very nicely with those estimated from EIS and reported in the same figure.

In spite of such a simplification, if we take into account that a value of $V_{\mathrm{fb}}=-0.245 \pm 0.005 \mathrm{~V}$ (SCE) was derived in very good agreement with those previously derived at higher 


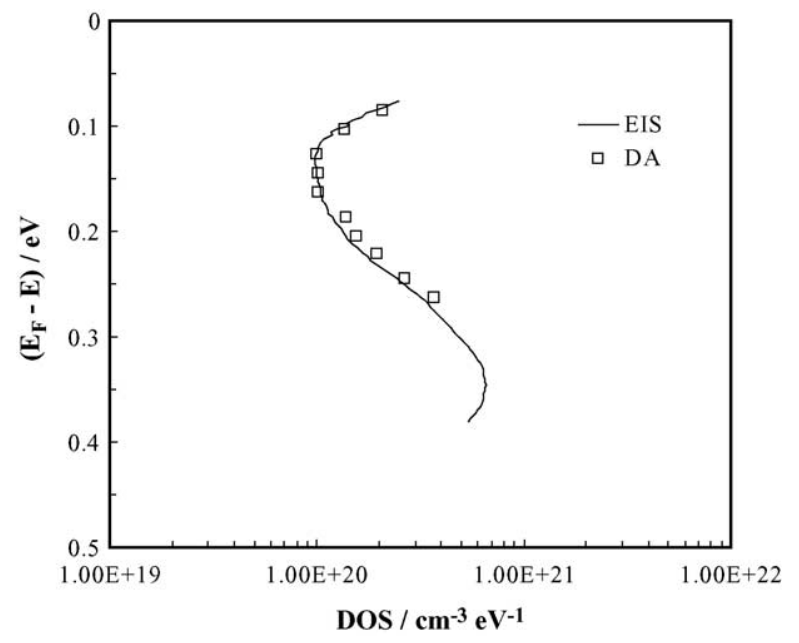

Fig. 16. Comparison of DOS distribution vs. energy obtained from EIS and differential conductance curves at $U_{\mathrm{E}}=5 \mathrm{~V}(\mathrm{SCE})$ and $10 \mathrm{~Hz} \leq f \leq 10 \mathrm{kHz}$.

frequencies, we can reasonably conclude that such a simplification should not heavily affect also the DOS estimate.

By looking to the results of DOS distribution reported in Fig. 14, it is possible to explain why Eqs. (8) and (9) obtained under the hypothesis of constant DOS $(N(E, x)=N)$ failed in fitting the admittance curves in a reasonably larger potential range. In fact the behaviour of $N\left(E, x_{\mathrm{C}}\right)$ versus $x_{\mathrm{C}}$ at any frequency (i.e. energy) displays large changes in values on going from $x_{\mathrm{C}}=0$ to $x_{\mathrm{C}}=D_{\mathrm{ox}}(N$ corresponding to this last value was derived by a polynomial best fitting of the experimental data usually covering between $50 \%$ and $70 \%$ of total film thickness at different thickness) with an almost spatially constant DOS usually limited in a range of $x_{\mathrm{C}} / D_{\mathrm{ox}} \leq 0.2$. In terms of band bending this region of constant DOS corresponds to potential drops ranging between 0.2 and $0.4 \mathrm{~V}$ from $V_{\mathrm{fb}}$.

A further confirm to this interpretation comes from a similar analysis performed on passive a- $\mathrm{WO}_{3}$ film when a fitting of $C_{\mathrm{SC}}$ plots in a range of potential of about $9 \mathrm{~V}$ was possible according to Eqs. (8) and (9) by using a constant DOS [7]. A similar interpretation could account also for the behaviour of thicker films of $\mathrm{a}-\mathrm{Nb}_{2} \mathrm{O}_{5}$ investigated in the low bandbending regime $[2,3]$ owing to the fact that in that case a small portion of the film beneath the surface was exploited by the admittance study. Further measurements are now in progress as a function of different anodizing parameters in order to understand such a behaviour as well as how the anodizing process influences the DOS distribution in a- $\mathrm{Nb}_{2} \mathrm{O}_{5}$ anodic films.

We like to comment on a last point related to the previous one. Although the variation of DOS for states lying deeper in energy $(10-100 \mathrm{~Hz}$ curves of Fig. 14) is similar to those higher in energy (1-10 kHz curves of Fig. 14) when extrapolated to $x_{\mathrm{C}}=D_{\mathrm{ox}}$ the number of states at these energy levels differs of about one order of magnitude (as already found from EIS data analysis). The origin of such a difference in value is yet not completely clear. We recently suggested that such a DOS, mimicking the mobile defects distribution foreseen theoretically by model of growth of anodic films in presence of mobile space charge, could be related to the existence of different types of mobile defects into a growing film $[7,22,23]$.

\section{Conclusions}

It has been shown by a detailed analysis of EIS spectra and differential admittance curves that the theory of amorphous Schottky barrier is able to explain the overall electrical behaviour of $a-\mathrm{Nb}_{2} \mathrm{O}_{5} / \mathrm{El}$ interface in the range of electrode potential from $U_{\mathrm{F}}$ to $V_{\mathrm{fb}}$ and ac frequency. By a careful study in a large span of frequency and voltage, a constant $V_{\mathrm{fb}}$ value for relatively thin $\left(D_{\mathrm{ox}} \leq 20 \mathrm{~nm}\right)$ anodic amorphous passive film has been determined. Such an accomplishment has been reached by introducing a spatially variable DOS both in modelling the EIS spectra as well as in fitting the differential admittance plots as a function of frequency and electrode potential. This extension of theory of a-SC Schottky barrier allowed for getting out a distribution of DOS which mimics the distribution of mobile defects during the growth of oxide film in presence of a space charge [23].

The results of this study are a further confirm that the simple Mott-Schottky analysis in presence of amorphous or strongly disordered films can provide, under special conditions, only qualitative information on the location of characteristic energy levels $\left(V_{\mathrm{fb}}, E_{\mathrm{C}}, E_{\mathrm{V}}\right)$ of semiconducting passive film/El junction. In these last cases we suggest that such very popular approach should be dismissed in favour of a more complex, but physically better grounded, approach based on a-SC Schottky barrier theory.

It is also in the scope of this work to show that an abandon of simple M-S model of analysis of data could also offers new insights for understanding the complex electrical behaviour of passive films as well as their mechanisms of growth and breakdown.

Further studies are now in progress on different systems in order to test the validity of model and hypothesis previously suggested.

\section{Appendix A}

\section{A.1. EIS data fitting procedure}

In order to fit the EIS data we used the method suggested in Ref. [16] to get the DOS distribution, $N(E)$, at each potential. According to this the following expression was used to estimate DOS at $x_{\mathrm{C}}$ :

$$
\begin{aligned}
N & \left(E_{\mathrm{F}}-e \psi_{\mathrm{C}}(\omega)\right) \\
& =\frac{2}{\pi k T} \frac{G(\omega) / \omega}{C(\omega)\left[1-\frac{x_{\mathrm{C}}}{\varepsilon \varepsilon_{0}} C(\omega)\right]} \int_{E_{\mathrm{F}}-e \psi_{\mathrm{C}}}^{E_{\mathrm{F}}} N(E) \mathrm{d} E \\
& =\frac{G(\omega)}{\omega} K(\omega)
\end{aligned}
$$


where the $C(\omega)$ and $G(\omega)$ values are those measured at each potential, and a trial estimate for DOS $N(E)=N$ was initially assumed.Eqs. (3) and (A.2):

$x_{\mathrm{C}}=x\left(\psi_{\mathrm{C}}\right)=\int_{\psi_{\mathrm{C}}}^{\psi_{\mathrm{S}}} \frac{\mathrm{d} \psi}{\left[\frac{2}{\varepsilon \varepsilon_{0}} \int_{0}^{\psi}\left(\int_{E_{\mathrm{F}}-e \psi^{\prime}}^{E_{\mathrm{F}}} N(E) \mathrm{d} E\right) \mathrm{d} \psi^{\prime}\right]^{\frac{1}{2}}}$

were used to obtain $\psi_{\mathrm{C}}$ from $\omega$ and $x_{\mathrm{C}}$ as a function of $\omega$, $\psi_{\mathrm{S}}$ and $N(E)$. An iterative technique was used to find the value of $N(E)$ and the iteration was stopped once a difference between the $(n-1)$ and $n$ estimate of $N(E)$ less than $1 \%$ was reached. The new value of DOS obtained after each iteration was used to calculate the $C_{\mathrm{SC}}(\omega)$ and $G_{\mathrm{SC}}(\omega)$ values to be used in the general equivalent circuit of Fig. 5 where constant $C_{\mathrm{H}}$ values (around $20 \mu \mathrm{F} \mathrm{cm}^{-2}$ ) were accepted, whilst all others elements were derived from the best fitting approach. The procedure was repeated until the error between simulated EIS spectra and measured EIS spectra was less than $5 \%$ in the $|Z|$ versus $\log (f)$ plot and $\pm 2^{\circ}$ in the $\phi(Z)$ versus $\log (f)$ plot. The optimisation of $Z_{\mathrm{el}}$ elements (see Fig. 6) was carried out by using the Z-SimpWin software package after subtracting to the equivalent circuit the $Z_{\mathrm{SC}}$ elements obtained after fitting of EIS data.

The range of frequency investigated $(0.1 \mathrm{~Hz}-100 \mathrm{kHz})$ allowed to calculate, at each potential, the DOS in a range of energy:

$E_{\mathrm{F}}-e \psi_{\mathrm{C}}\left(10^{-1} \mathrm{~Hz}\right)<E<E_{\mathrm{F}}-e \psi_{\mathrm{C}}\left(10^{5} \mathrm{~Hz}\right)$

The minimum value of electrode polarization still compatible with the constraints of the theory $\left(\psi_{\mathrm{S}} \geq \psi_{\mathrm{C}} \geq 3 \mathrm{kT} / \mathrm{e}\right.$ ) which allowed to exploit experimentally the largest energy range of DOS to be used in fitting the EIS data was $U_{\mathrm{E}}=0.18 \mathrm{~V}(\mathrm{SCE})$. In fact at this potential $\psi_{\mathrm{S}}=0.43 \mathrm{~V}$, which is still $0.05 \mathrm{~V}$ higher than the $\psi_{\mathrm{C}}$ value estimated at the lower frequency. Outside the energy range accessible by direct measurements (see Fig. 17) the real DOS has been approximated by assuming a gaussian distribution around the observed maximum in DOS followed by a constant DOS at still lower energies.

The assumption of a constant DOS at the lowest energies (experimentally not accessible region) is a little arbitrary but not relevant to our aims, because its exact shape does not affect the response of barrier provided that the total amount of deep-lying states is more or less the same than that of the exploited DOS distribution.

By assuming in the deep energy region a constant DOS about three times higher (see in Fig. 17) than that estimated by EIS (continuos line) an error in the $|Z|$ around $5 \%$ was obtained.

\section{A.2. Differential admittance curves fitting}

The fitting of $C_{\mathrm{SC}}\left(\omega, \psi_{\mathrm{S}}\right)$ and $G_{\mathrm{SC}}\left(\omega, \psi_{\mathrm{S}}\right)$ at different frequencies $(10 \mathrm{~Hz} \leq f \leq 10 \mathrm{kHz})$ was carried out by using

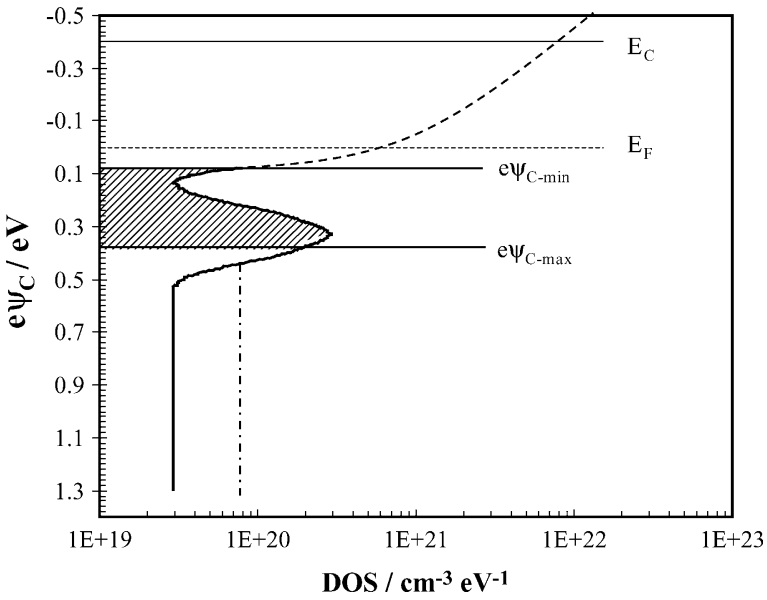

Fig. 17. DOS distribution used for fitting EIS data. Dashed area represents the experimentally probed region; (-- -): qualitative expected behaviour; (....-): hypothetical DOS at which an error of $5 \%$ was measured in $|Z|$ vs. $\log f$ plot (see Appendix A).

Eqs. (8) and (9) modified as:

$\frac{1}{C\left(x, \omega, \psi_{\mathrm{S}}\right)}=\frac{1}{C\left(\omega, \psi_{\mathrm{S}}\right)} f_{\omega}\left(x\left(\psi_{\mathrm{S}}\right)\right)$

$G\left(x, \omega, \psi_{\mathrm{S}}\right)=G\left(\omega, \psi_{\mathrm{S}}\right) g_{\omega}\left(x\left(\psi_{\mathrm{S}}\right)\right)$

where $f \omega\left(x\left(\psi_{\mathrm{S}}\right)\right)$ and $g \omega\left(x\left(\psi_{\mathrm{S}}\right)\right)$ are, respectively, two different trial functions depending only on electrode potential but changing with employed frequency. The term multiplying the two trial functions can be considered as coincident with the expression of $\left(C_{\mathrm{SC}}\right)^{-1}$ and $G_{\mathrm{SC}}$ in absence of spatial variation in DOS (homogeneous film) but averaged in energy $(N(E)=\bar{N})$.

The DOS at $x_{\mathrm{C}}, N\left(E_{\mathrm{F}}-e \psi_{\mathrm{C}}\right)$, were obtained by using Eq. (34) of Ref. [15] rewritten as:

$$
\begin{aligned}
N\left(E_{\mathrm{F}}-e \psi_{\mathrm{C}}\right)= & \frac{2}{\pi k T} \frac{G\left(\psi_{\mathrm{S}}, \omega\right) / \omega}{C^{2}\left(\psi_{\mathrm{S}}, \omega\right)} f_{\omega}\left(x\left(\psi_{\mathrm{S}}\right)\right) C\left(\psi_{\mathrm{C}}, 0\right) \\
& \times \int_{E_{\mathrm{F}}-e \psi_{\mathrm{C}}}^{E_{\mathrm{F}}} N(E) \mathrm{d} E
\end{aligned}
$$

and by substituting to the integral the term $e \psi_{\mathrm{C}} \bar{N}(x)$. As first approximation for $\bar{N}(x)$ that one derived from the fitting of $C_{\mathrm{SC}}$ at the same $\omega$ and $x_{\mathrm{C}}$ have been chosen.

The other fitting parameters $\left(V_{\mathrm{fb}}, V_{\mathrm{g}}, \psi_{\mathrm{C}}\right)$ were chosen trough an educated guess procedure by taking into account that:

(a) as for the $\psi_{\mathrm{C}}$ parameter the constraint of a decrease of $0.06 \mathrm{eV}$ for decade of frequency was introduced in the fitting procedure and a check of the acceptability of the $\psi_{\mathrm{C}}$ choice was the prediction of flattening of capacitance curves at the frequency corresponding to $\psi_{\mathrm{C}}=0$;

(b) the $V_{\mathrm{g}}$ parameter was calculated by assuming an equal emission-capture time constant for electrons and hole in 
the conduction and in valence band [14] and by using a measured mobility gap for $\mathrm{a}-\mathrm{Nb}_{2} \mathrm{O}_{5}$ film equal to $3.40 \mathrm{eV}$;

(c) the $V_{\mathrm{fb}}$ value for fitting the $C_{\mathrm{SC}}\left(x, \omega, \psi_{\mathrm{S}}\right)$ and $G_{\mathrm{SC}}(x, \omega$, $\left.\psi_{\mathrm{S}}\right)$ curves was allowed to differ no more than $0.025 \mathrm{~V}$.

\section{References}

[1] F. Di Quarto, M. Santamaria, Corros. Eng. Sci. Technol. 39 (2004) 71

[2] F. Di Quarto, C. Sunseri, S. Piazza, Ber. Bunsenges. Phys. Chem. 90 (1986) 549.

[3] F. Di Quarto, S. Piazza, C. Sunseri, Electrochim. Acta 35 (1990) 97.

[4] F. Di Quarto, V.O. Aimiuwu, S. Piazza, C. Sunseri, Electrochim. Acta 36 (1991) 1817

[5] S. Piazza, C. Sunseri, F. Di Quarto, AIChE J. 38 (1992) 219.

[6] J. Sikora, E. Sikora, D.D. Macdonald, Electrochim. Acta 45 (2000) 1875.

[7] F. Di Quarto, M. Santamaria, in: V. Birss, L. Burke, A.R. Hillman, R.S. Lillard (Eds.), ECS PV 2003-25, 2004, p. 116.

[8] L. Young, Anodic Oxide Films, Academic Press, London, New York, 1961.

[9] S. Ono, M. Baba, M. Shimiyama, H. Asoh, in: V. Birss, L. Burke, A.R. Hillman, R.S. Lillard (Eds.), ECS PV 2003-25, 2004, p. 133.
[10] H. Habazaki, T. Matsuo, H. Konno, K. Shimizu, S. Nagata, K. Matsumoto, K. Takayama, Y. Oda, Abs. S7FP67 of 55th ISE Meeting, 19-24 September 2004 Thessaloniki.

[11] C.O.A. Olsson, M.G. Verge, D. Landolt, J. Electrochem. Soc. 151 (2004) B652.

[12] F. Di Quarto, C. Sunseri, S. Piazza, M. Santamaria, in: H.S. Nalwa (Ed.), Handbook of Thin Films, vol. 2, Academic Press, 2002, pp. 373-414.

[13] W.E. Spear, S.H. Baker, Electrochim. Acta 34 (1989) 1691.

[14] J.D. Cohen, D.V. Lang, Phys. Rev. B 25 (1982) 5321.

[15] W. Archibald, R.A. Abram, Phil. Mag. B 48 (1983) 111.

[16] W. Archibald, R.A. Abram, Phil. Mag. B 54 (1986) 421; W. Archibald, R.A. Abram, Phil. Mag. B 56 (1987) 429.

[17] C. Da Fonseca, M. Guerreiro Ferreira, M. Da Cunha Belo, Electrochim. Acta 39 (1994) 2197.

[18] W.P. Gomes, D. Vanmaekelbergh, Electrochim. Acta 41 (1996) 967.

[19] G. Oskam, D. Vanmaekelbergh, J.J. Kelly, Electrochim. Acta 38 (1992) 301

[20] Y.M. Li, L. Young, J. Electrochem. Soc. 147 (2000) 1344.

[21] T. Hurlen, H. Bentzen, S. Hornkjøl, Electrochim. Acta 32 (1987) 1614.

[22] M.J. Dignam, Oxides and Oxide Films, vol. 1, Marcel Dekker Inc., New York, 1972, p. 190

[23] T. Fromhold, Oxide and Oxide Films, vol. 3, Marcel Dekker Inc., New York Basel, 1976. 